\title{
Influence of the Sintering Temperature on the Magnetic and Electric Properties of $\mathrm{NiFe}_{2} \mathrm{O}_{4}$ Ferrites
}

\author{
Fabio Luis Zabotto*, Alexandre José Gualdi, Jose Antonio Eiras, \\ Adilson Jesus Aparecido de Oliveira, Ducinei Garcia \\ Physics Department, Federal University of São Carlos - UFSCar, \\ CEP 13565-905, São Carlos, SP, Brazil
}

Received: September 13, 2011; Revised: March 12, 2012

\begin{abstract}
This study evaluates the structural, microstructural, electric and magnetic properties of nickel ferrite samples prepared through the solid state reaction. It was observed that an increase in the sintering temperature produces a higher cation concentration in the A site when compared to the B site. The assessment of magnetic properties showed that an increase in grain size leads to a decrease in the coercive fields verging on superparamagnetic values, while the saturation magnetization increases up to $46.5 \mathrm{Am}^{2} \cdot \mathrm{kg}^{-1}$ for samples sintered at $1200{ }^{\circ} \mathrm{C}$. The dc electric resistivity behavior of samples was attributed to the increase in the cross-sectional area of grains as well as the different oxidation states and distribution of cations amongst the lattice sites of the spinel structure.
\end{abstract}

Keywords: processing, nickel ferrites, magnetic properties, electric resistivity

\section{Introduction}

Me-ferrites are magnetic materials with the generic structure $\mathrm{MeFe}_{2}^{+3} \mathrm{O}_{4}$, where $\mathrm{Me}$ can be $\mathrm{Ni}^{+2}, \mathrm{Cu}^{+2}, \mathrm{Mg}^{+2}$ or $\mathrm{Co}^{+2}$. They are of great interest to researchers due to their wide range of applications in many fields, including information and communication devices, information storage, and ferrofluids ${ }^{1-3}$. These materials present high levels of magnetic permeability, saturation magnetization and electric resistivity ${ }^{4-6}$. In addition to these properties, Me-ferrites show large magnetostrictive coefficients ${ }^{7}$, thus allowing for applications in transducer devices. Recently, ferrites have also been used as the magnetic phase in composites with magnetoelectric effect ${ }^{8,9}$. In these systems, the high conversion energy coefficient between electric and magnetic fields (ME effect) is directly dependent on the high electric resistivity, high saturation magnetization (Ms) and high magnetostrictive coefficient of the magnetic phase, as well as the chemical stability of the magnetic phases ${ }^{8,9}$.

Me-ferrites in polycrystalline form may be obtained by several preparation methods, such as solid state reaction, co-precipitation, mechano-chemical, combustion, or sol-gel ${ }^{10-13}$. However, variations in synthesis conditions such as sintering time, temperature, atmosphere and thermal annealing will influence final composition and grain size ${ }^{13,14}$.

One of the most important members of Me-Ferrite systems is the nickel ferrite, or $\mathrm{NiFe}_{2} \mathrm{O}_{4}$, which is a soft magnetic material with an inverse spinel structure. Ferrimagnetism originates from magnetic moments of antiparallel spins between $\mathrm{Fe}^{3+}$ ions at tetrahedral sites and $\mathrm{Ni}^{2+}$ ions at octahedral sites ${ }^{3,14}$. In this system, an increase in grain size leads to a decrease in the coercive field, while saturation

*e-mail: zabotto@df.ufscar.br magnetization increases. In Ni-Zn ferrites, on the other hand, an increase in the sintering temperature leads to a decrease in the resistivity due to the higher $\mathrm{Fe}^{2+}$ concentration, allowing hopping conductivity mechanisms to occur ${ }^{15,16}$.

Several investigations on the structure, conductivity and magnetic properties of Ni-modified ferrites have been reported in literature ${ }^{13-16}$. Most reports, however, describe the obtaining and characterization of nanoparticles through several processing routes ${ }^{14,17-20}$.This paper investigates the effect of the sintering temperature of Ni-ferrite bulk ceramics upon microstructural evolution, and evaluates its relation with electric and magnetic properties as well.

\section{Experimental Procedure}

Powder with a nominal composition of $\mathrm{NiFe}_{2} \mathrm{O}_{4}$ was prepared through the solid state reaction method using $\alpha-\mathrm{Fe}_{2} \mathrm{O}_{3}(99.98 \%)$ and $\mathrm{NiO}(99.99 \%)$ as precursors. The powders were ball-milled within polyethylene pots filled with distilled water and zirconia balls, in the correct composition, for 3 hours, and then calcined at $900{ }^{\circ} \mathrm{C}$ for 4 hours. The ferrite powder was then ball-milled at $200 \mathrm{rpm}$ for 10 hours and then dried. The specimens were compacted by uniaxial pressing and isostatic pressing to minimize density gradients. Later, the specimens were fired by conventional sintering from 1000 to $1200{ }^{\circ} \mathrm{C}$ for 4 hours.

The crystalline phases of the sintered specimens were determined through X-ray diffraction (XRD) performed in a Rigaku Rotaflex RU200B diffractometer, with $\mathrm{CuK}_{\text {}}$ radiation $(0.15418 \mathrm{~nm})$. The grains size distribution and morphology were observed by scanning electron microscopy 
(SEM), for samples optically polished and thermally etched. The apparent density $\left(\rho_{\text {app }}\right)$ of sintered ceramic bodies was obtained by the Archimedes method, with distilled water as the immersion liquid. The electric resistivity measurements, at room temperature with an applied dc field, were performed on the gold sputtered ceramics using a Model 617 Keithley electrometer. Magnetic hysteresis was measured with a Model 7100 Quantum Design Physical Properties Measurement System (PPMS) dc extraction magnetometer, at $300 \mathrm{~K}$, up to $50 \mathrm{kOe}$.

\section{Results}

The XRD patterns of the sintered ceramics are shown in Figure 1. The sharp peaks indicate well-crystallized grains. All peaks are identified as the typical cubic-spinel structure, as expected for $\mathrm{NiFe}_{2} \mathrm{O}_{4}$. No other diffraction lines were observed, suggesting the absence of spurious phases in the samples at observable XRD levels. As seen on Table 1, the lattice parameter $a$, determined from the XRD patterns, increases for sintering temperatures up to $1150{ }^{\circ} \mathrm{C}$ and then slightly decreases for the sample sintered at $1200^{\circ} \mathrm{C}$. Small changes in lattice parameter $a$ may be related to the oxidation states and distribution of cations amongst the lattice sites of the spinel structure. Up to $1150{ }^{\circ} \mathrm{C}$, the increase in the lattice parameter $a$ is mainly related to iron reduction from $\mathrm{Fe}^{3+}$ to $\mathrm{Fe}^{2+}$ during the sintering process, since the $\mathrm{Fe}^{+2}$ ion has a larger ionic radius $(0.76 \AA)$ than $\mathrm{Fe}^{+3}(0.64 \AA)^{21}$. For

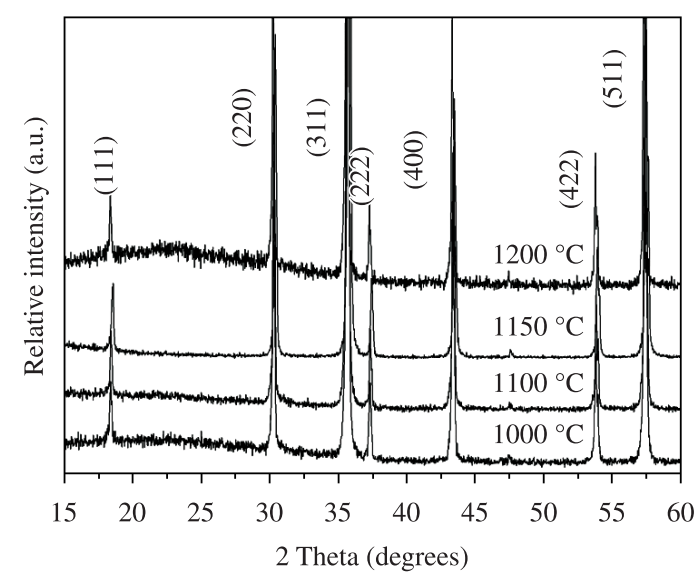

Figure 1. XRD patterns of the Ni-ferrite ceramics conventionally sintered at several temperatures, for 4 hours. The indexing is based on the JCPDS file \# 441485. Source: F. L. Zabotto et al.

Table 1. Apparent relative density, lattice parameter $a$, relative intensity of the 200 and 222 planes, or $\mathrm{I}_{220} / \mathrm{I}_{222}$ for $\mathrm{NiFe}_{2} \mathrm{O}_{4}$ ceramics conventionally sintered at different temperatures, for 4 hours.

\begin{tabular}{cccc}
\hline $\begin{array}{c}\text { Sintering } \\
\text { temperature }\left({ }^{\circ} \mathbf{C}\right)\end{array}$ & $\begin{array}{c}\text { Relative } \\
\text { density } \\
(\%)\end{array}$ & $\begin{array}{c}\boldsymbol{a} \text { Cell } \\
\text { parameter }(\AA)\end{array}$ & $I_{220} / I_{222}$ \\
\hline 1000 & $90.0 \pm 0.4$ & $8.31 \pm 0.01$ & 3.20 \\
1100 & $93.1 \pm 0.3$ & $8.33 \pm 0.01$ & 3.29 \\
1150 & $95.0 \pm 0.2$ & $8.35 \pm 0.01$ & 3.60 \\
1200 & $96.2 \pm 0.2$ & $8.34 \pm 0.01$ & 3.60 \\
\hline
\end{tabular}

Source: F. L. Zabotto et al. sintering temperatures higher than $1150{ }^{\circ} \mathrm{C}$, the formation of $\mathrm{Ni}^{+3}(0.62 \AA)$ is likely to occur, resulting in the reduction of the lattice parameter $a$. The values of the intensity ratio $\left(\mathrm{I}_{220} / \mathrm{I}_{222}\right)$, which can characterize the cation distribution of $\mathrm{NiFe}_{2} \mathrm{O}_{3}{ }^{[22]}$, are given in Table 1 . The intensity of (220) and (222) planes depends on the cation distribution in the tetrahedral (A) and octahedral sites (B), respectively ${ }^{22}$. The calculated values lie between 3.20 and 3.60, and they show an increase with the sintering temperature. The observed values are compatible with the reported values $(0.8-3.6)^{22}$. The increase in the $\mathrm{I}_{220} / \mathrm{I}_{222}$ ratio with sintering temperature indicates that the cation concentration in the A site increases when compared to the B site, and this fact may suggest the formation of a blend of the normal and inverse spinel structure, or mixed spinel structure.

The apparent density values for different sintering conditions are shown on Table 1. The values show that the apparent density of the samples increases at higher sintering temperatures. High density values ( $>95 \%)$ were found for sintering temperatures above $1150{ }^{\circ} \mathrm{C}$, which is in agreement with the shrinkage curve (not shown here), where the maximum shrinkage ratio occurs close to $1150^{\circ} \mathrm{C}$.

SEM surface micrographs of Ni-ferrites sintered at $1000,1100,1150$ and $1200{ }^{\circ} \mathrm{C}$ for 4 hours are shown in Figure $2 \mathrm{a}-\mathrm{d}$. The increase in average grain size following the raises in sintering temperatures is clearly visible, from $\sim 0.3 \mu \mathrm{m}$ for samples sintered at $1000{ }^{\circ} \mathrm{C}$ to $\sim 2-3 \mu \mathrm{m}$ for samples sintered at $1200{ }^{\circ} \mathrm{C}$. The micrographs of the samples sintered at 1000 and $1100{ }^{\circ} \mathrm{C}$ show microstructures with small grains ( $\sim 0.3$ and $0.7 \mu \mathrm{m}$, respectively) and open porosity due to intra-granular pores, indicating that the sintering temperatures were insufficient for the complete formation of a dense microstructure, which is consistent with the low relative density values measured. The sample sintered at $1150{ }^{\circ} \mathrm{C}$ shows two distinct average grain size distributions and some pores. The grains with an average size close to $1.5 \mu \mathrm{m}$ are surrounded by smaller grains of average grain size close to $0.8 \mu \mathrm{m}$. The large grains may be associated with grain growth from the smaller grains, or may be an agglomerate of small grains. On the other hand, the sample sintered at $1200{ }^{\circ} \mathrm{C}$ showed a dense microstructure (in agreement with the apparent density values) and larger grain sizes $(\sim 2-3 \mu \mathrm{m})$, however inter-granular pores of low coordination number starts to appear. The increase in average grain size and stabilization of the apparent density indicate the final stage of sintering ${ }^{23}$.

The magnetic hysteresis loop, at room temperature, of the $\mathrm{NiFe}_{2} \mathrm{O}_{4}$ samples sintered at 1000, 1100, 1150 and $1200{ }^{\circ} \mathrm{C}$, is shown in Figure 3. A soft ferromagnetic hysteresis can be seen in all samples, as expected from a ferrite system ${ }^{3}$. The measured saturation magnetization $\left(\mathrm{M}_{\mathrm{s}}\right)$ at $800 \mathrm{kA} \cdot \mathrm{m}^{-1}$ and coercitivity $\left(\mathrm{H}_{\mathrm{c}}\right)$ values of the samples are given in Table 2. An increase in the sintering temperature from 1000 to $1200{ }^{\circ} \mathrm{C}$ reduces the value of the $\mathrm{H}_{\mathrm{c}}$ by about $90 \%$, verging on superparamagnetic values ${ }^{18-22}$, as seen in Figure 4. This decrease can be attributed mainly to an increase in the grain size of samples. It is known that the grain size increases with sintering temperature, and larger grains tend to consist of a greater number of domain walls. The magnetization caused by domain wall movement 


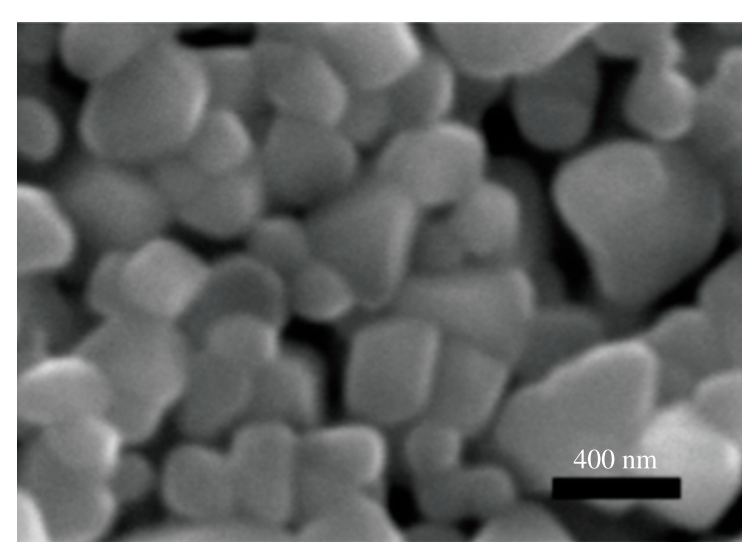

(a)

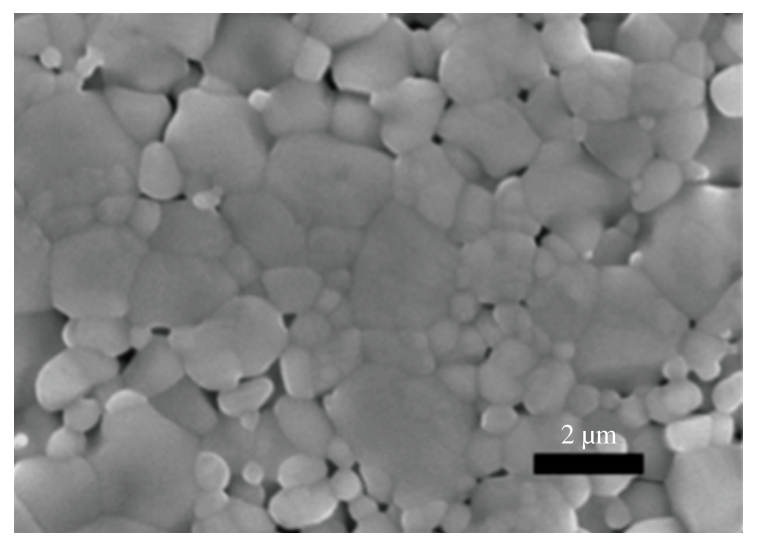

(c)

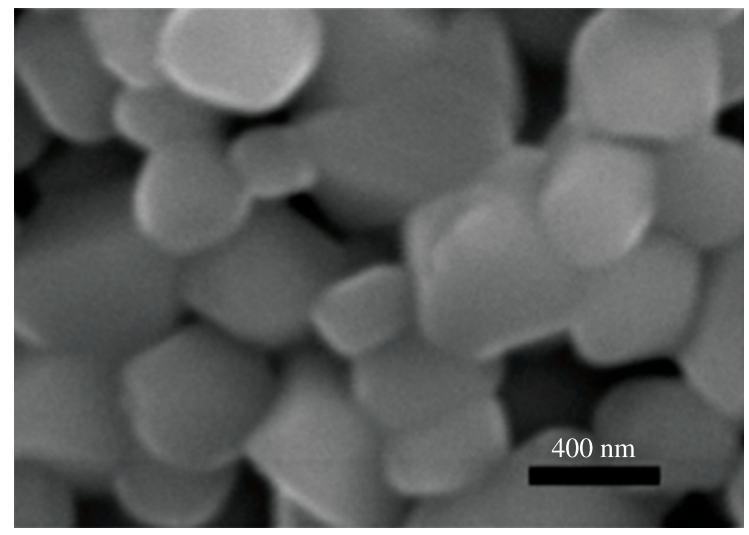

(b)

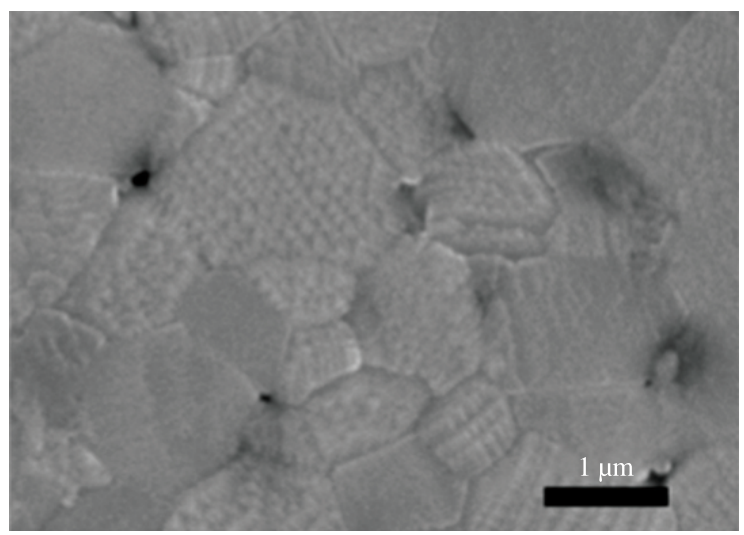

(d)

Figure 2. SEM surface images of Ni-ferrite sintered for 4 hours at: a) $1000^{\circ} \mathrm{C}$; b) $1100^{\circ} \mathrm{C}$; c) $1150^{\circ} \mathrm{C}$; and d) $1200^{\circ} \mathrm{C}$. Source: F. L. Zabotto et al.

requires less energy than that required by domain rotation. As the number of walls increases with grain size, the contribution of wall movement to magnetization is greater than that of domain rotation. Therefore, samples having larger grains are expected to have a low coercivity, $\mathrm{H}_{\mathrm{c}}$. Also, it can be seen that the saturation magnetization increases by aproximately $10 \%$, from 42 to 46 to $\mathrm{Am}^{2} \cdot \mathrm{kg}^{-1}$, with the increase in sintering temperatures. These $\mathrm{M}_{\mathrm{s}}$ values are consistent with previous reports on the magnetic behavior of $\mathrm{NiFe}_{2} \mathrm{O}_{4}$ bulk ferrites ${ }^{6,7}$. On the other hand, observed $\mathrm{M}_{\mathrm{s}}$ is found to be higher than that of the $\mathrm{NiFe}_{2} \mathrm{O}_{4}$ prepared by the sol-gel auto-combustion method $\left(7.39 \mathrm{Am}^{2} . \mathrm{kg}^{-1}\right)$ and by the facile oxalate decomposition method $\left(4 \mathrm{Am}^{2} \cdot \mathrm{kg}^{-1}\right)^{22}$. The higher $\mathrm{M}_{\mathrm{s}}$ values obtained for samples sintered at high sintering temperatures may be associated with the different oxidation states and distribution of cations amongst the lattice sites of the spinel structure, as suggested by the XRD analyses. The different oxidation states and distribution of cations amongst the lattice sites may be generating a mixed spinel structure. It is known that the net magnetization of pure inverse spinel $\mathrm{NiFe}_{2} \mathrm{O}_{4}$ is mainly due to $\mathrm{Ni}^{+2}$ moments in the $\mathrm{B}$ site only. Hence, $\mathrm{Fe}^{+3}$ moments from the $\mathrm{A}$ and $\mathrm{B}$ sites cancel each other and give lower magnetization values than those of the mixed spinel $\mathrm{NiFe}_{2} \mathrm{O}_{4}$. In the case of mixed spinel structure, the saturation magnetization value is high due to the presence, for example, of the $\mathrm{Ni}^{+2}$ ions in the
A sites ${ }^{22}$. The high saturation values $\left(\sim 46 \mathrm{Am}^{2} \cdot \mathrm{kg}^{-1}\right)$, together with the absence of the hysteresis area and the almost immeasurable coercitivity observed for samples sintered at $1200{ }^{\circ} \mathrm{C}$ suggests a superparamagnetic-like behavior. However, such behavior generally occurs in nanoparticles due to the fact that these particles have a single domain structure $^{19,20}$. To the best of our knowledge, bulk $\mathrm{NiFe}_{2} \mathrm{O}_{4}$ with such a high saturation magnetization and very low coercitivity has not been reported.

Figure 5 shows the electric resistivity at room temperature, as a function of sintering temperature. The results confirm a gradual decrease in electric resistivity, from values $\sim 2.4 \times 10^{6} \Omega \mathrm{m}$ to $0.3 \times 10^{6} \Omega \mathrm{m}$, for high sintering temperatures. The variation in resistivity can be explained as a consequence of microstructural and structural shifts resulting from changes in sintering conditions. Decreased porosity causes individual grains to come closer, while the increased average grain size reduces the grain boundary. These two characteristics combined increase the cross-sectional area of the conductor, thus causing a decrease in the total resistance of the sample. Additionally, the raise in sintering temperatures may be increasing $\mathrm{Fe}^{+2}$ concentrations, allowing a hopping-type conduction between $\mathrm{Fe}^{+3}$ and $\mathrm{Fe}^{+2}$, as suggested by XRD analyses. The electric conductivity in ferrites can be explained by the Verwey-de Boer mechanism in which 


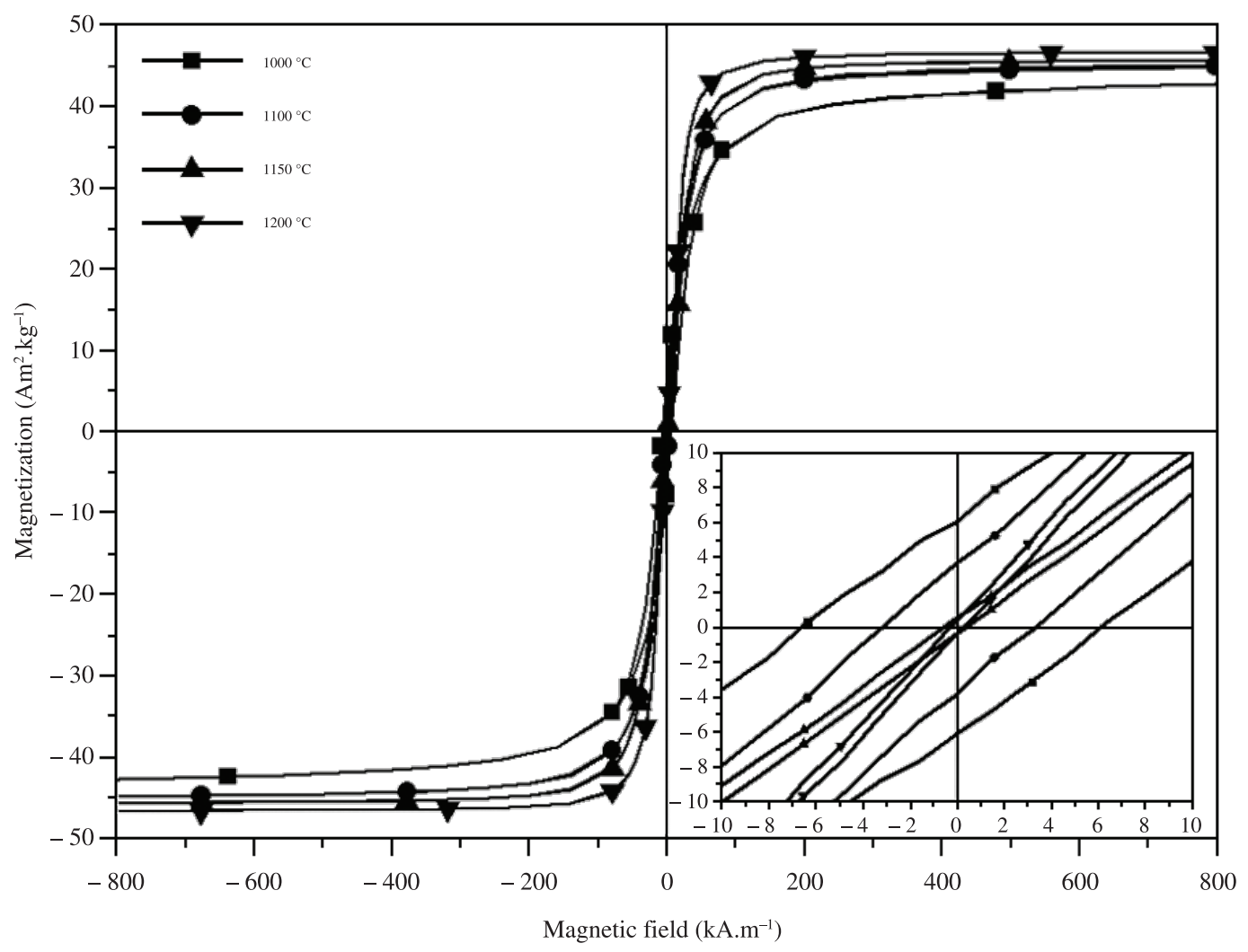

Figure 3. Magnetization as a function of applied magnetic field at room temperature for Ni-ferrite samples sintered at different sintering temperatures for 4 hours. Source: F. L. Zabotto et al.

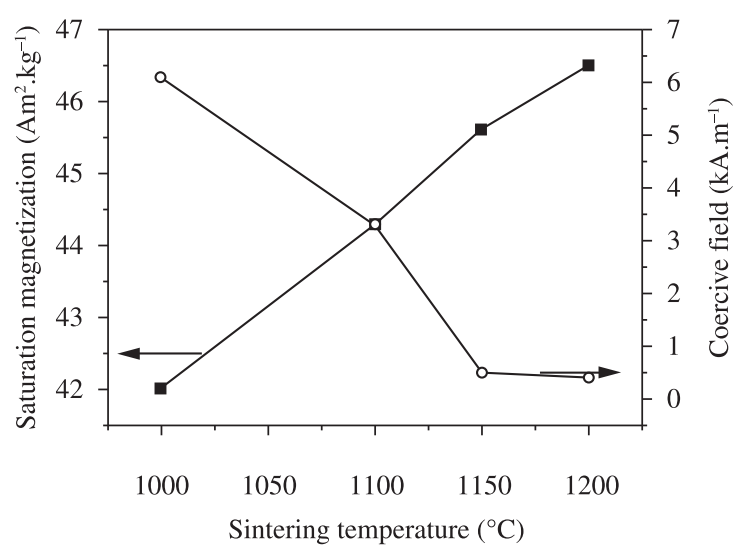

Figure 4. Saturation magnetization and coercive field as a function of the sintering temperature for Ni-ferrite samples sintered at different sintering temperatures for 4 hours. Source: F. L. Zabotto et al.

electron exchanges takes place between ions of the same element present in more than one valence state ${ }^{3,24}$. Such ions are distributed randomly over crystallographically equivalent lattice sites and, in nickel ferrites, the electronic hopping between $\mathrm{Fe}^{+2}$ and $\mathrm{Fe}^{+3}$ ions located on octahedral sites is the primary mechanism which allows electrical transport ${ }^{24-26}$. The activation energy (Ea), estimated by an
Table 2. Activation energy, electric resistivity at room temperature, saturation magnetization and coercive field as a function of sintering temperature for $\mathrm{NiFe}_{2} \mathrm{O}_{4}$ ceramics.

\begin{tabular}{ccccc}
\hline $\begin{array}{c}\text { Sintering } \\
\text { condition } \\
\left({ }^{\circ} \mathbf{C}\right)\end{array}$ & $\begin{array}{c}\text { Activation } \\
\text { energy } \\
(\mathbf{e V})\end{array}$ & $\begin{array}{c}\text { Room } \\
\text { temperature } \\
\text { resistivity } \\
\left(\times \mathbf{1 0}^{\mathbf{6}} \Omega \mathbf{m}\right)\end{array}$ & $\begin{array}{c}\text { Saturation } \\
\text { magnetization } \\
\left(\mathbf{A m}^{\mathbf{2}} \cdot \mathbf{k g}^{-1}\right)\end{array}$ & $\begin{array}{c}\text { Coercive } \\
\text { field } \\
\left(\mathbf{k A . m ^ { - 1 } )}\right.\end{array}$ \\
\hline 1000 & 0.52 & $2.43 \pm 0.06$ & 42.0 & 6.1 \\
1100 & 0.39 & $1.32 \pm 0.02$ & 44.3 & 3.3 \\
1150 & 0.35 & $0.58 \pm 0.07$ & 45.5 & 0.5 \\
1200 & 0.28 & $0.3 \pm 0.1$ & 46.5 & 0.4 \\
\hline
\end{tabular}

Source: F. L. Zabotto et al.

Arrhenius-type calculation for electric conductivity, $\sigma$, i.e. $\sigma=\sigma_{0} \exp \left[-\frac{E_{a}}{k_{B} T}\right]$, between $20^{\circ} \mathrm{C}$ and $130{ }^{\circ} \mathrm{C}$, shown in Table 2, also decreases as the sintering temperature is raised. The activation energy of the samples sintered at $1200{ }^{\circ} \mathrm{C}(0.28 \mathrm{eV})$ is lower than that of samples sintered at $1000{ }^{\circ} \mathrm{C}(0.52 \mathrm{eV})$. This showed that more energy was required for electron hopping between $\mathrm{Fe}^{+2}$ and $\mathrm{Fe}^{+3}$ ions in samples sintered at lower temperatures. The result is consistent with the conclusion that the higher activation energy is associated with higher electrical resistivity ${ }^{24}$. 


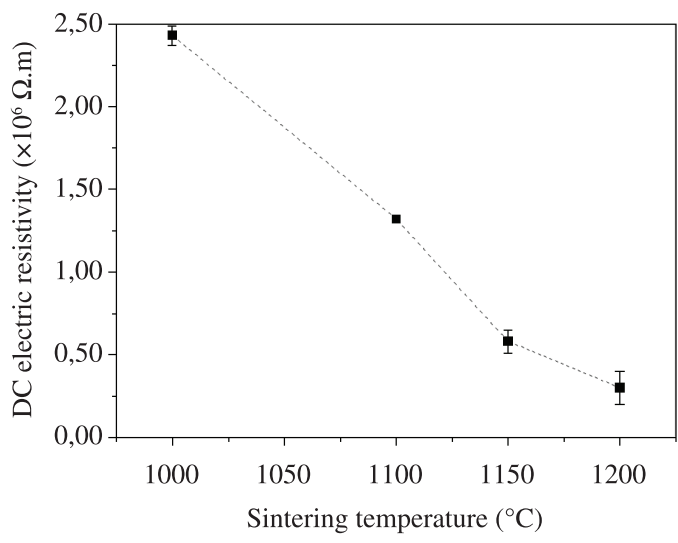

Figure 5. Dc electric resistivity as a function of sintering temperature for $\mathrm{Ni}$-ferrite samples sintered at different sintering temperatures for 4 hours. Source: F. L. Zabotto et al.

\section{Conclusion}

Ni-ferrite samples in bulk form have been prepared by solid state reaction, and the effect of the sintering temperature on its microstructural, electric and magnetic

\section{References}

1. Thang PD, Rijnders G and Blank DHA. Spinel cobalt ferrite by complexometric synthesis. Journal of Magnetism and Magnetic Materials. 2005; 295:251-256. http://dx.doi.org/10.1016/j. jmmm.2005.01.011

2. Berbenni V, Milanese C, Bruni G and Marini A.The combined effect of mechanical and thermal energy on the solid-state formation of $\mathrm{NiFe}_{2} \mathrm{O}_{4}$ from the system $2 \mathrm{NiCO}_{(3)}$ center dot $3 \mathrm{Ni}(\mathrm{OH})_{(2)}$ center dot $4 \mathrm{H}_{(2)} \mathrm{O}-\mathrm{FeC}_{2} \mathrm{O}_{4}$ center dot $2 \mathrm{H}_{(2)}$ O. Thermochimica Acta. 2008; 469:86-90. http://dx.doi. org/10.1016/j.tca.2007.11.025

3. Moulson AJ and Herbert JM. Electroceramics. 2nd ed. Chichester: John Wiley \& Sons Ltd; 2003.

4. Hessien MM, Rashad MM, El-Barawy K and Ibrahim IA. Influence of manganese substitution and annealing temperature on the formation, microstructure and magnetic properties of Mn-Zn ferrites. Journal of Magnetism and Magnetic Materials. 2008; 320:1615-1621. http://dx.doi.org/10.1016/j. jmmm.2008.01.025

5. Yadoji P, Peelamedu R, Agrawal D and Roy R. Microwave sintering of Ni-Zn ferrites: comparison with conventional sintering. Materials Science and Engineering: B. 2003; 98:269-278. http://dx.doi.org/10.1016/S09215107(03)00063-1

6. Corso S, Tailhades P, Pasquet I, Rousset A, Laurent V, Gabriel A et al.Preparation conditions of pure and stoichiometric $\mathrm{Ni}_{\mathrm{x}} \mathrm{Fe}_{3-\mathrm{x}} \mathrm{O}_{4}$ bulk ceramics. Solid State Sciences. 2004; 6:791-798. http://dx.doi.org/10.1016/j.solidstatesciences.2004.03.037

7. Smith $\mathrm{AB}$ and Jones RV. Magnetostriction in Nickel Ferrite and Cobalt-Nickel Ferrite. Journal of Applied Physics. 1966; 37:1001-1002. http://dx.doi. org/10.1063/1.1708305

8. Priya S, Islam R, Dong SX and Viehland D. Recent advancements in magnetoelectric particulate and laminate composites. Journal of Electroceramics. 2007; 19:147-164. http://dx.doi.org/10.1007/s10832-007-9042-5 properties has been investigated. High values of relative density were obtained for samples sintered at $1200{ }^{\circ} \mathrm{C}$. At higher sintering temperatures, the coercive field is reduced as a result of the increase in the domain size, which in turn is a consequence of grain growth. Samples sintered at $1200{ }^{\circ} \mathrm{C}$ showed a coercive field verging on superparamagnetic values, yet keeping the high values of saturation magnetization, as a consequence of the possible formation of a mixed spinel structure. As reported in literature, the dc electric resistivity of samples is influenced by both microstructural properties and different oxidation states of ions that support the electronic hopping conduction process.

\section{Acknowledgements}

The authors would like to thank the CNPq and FAPESP Brazilian agencies for financial support, Dr. Y. P. Mascarenhas (IFSC-USP) for XRD facilities, and Mr. F. J. Picon and Ms. N. A. Zanardi for technical support.

9. Nan CW, Bichurin MI, Dong SX, Viehland D and Srinivasan G. Multiferroic magnetoelectric composites: Historical perspective, status, and future directions. Journal of Applied Physics. 2008; 103:031-101. http://dx.doi. org/10.1063/1.2836410

10. Congiu F, Concas G, Ennas G, Falqui A, Fiorani D, Marongiu $\mathrm{G}$ et al. Magnetic properties of nanocrystalline $\mathrm{CoFe}_{2} \mathrm{O}_{4}$ dispersed in amorphous silica. Journal of Magnetism and Magnetic Materials. 2004; 272(76):1561-1562. http://dx.doi. org/10.1016/j.jmmm.2003.12.267

11. Yan CH, Xu ZG, Cheng FX, Wang ZM, Sun LD, Liao CS et al. Nanophased, $\mathrm{CoFe}_{2} \mathrm{O}_{4}$ prepared by combustion method. Solid State Communications. 1999; 111:287-291. http://dx.doi. org/10.1016/S0038-1098(99)00119-2

12. Cheng FX, Peng ZY, Liao CS, Xu ZG, Gao S, Yan $\mathrm{CH}$ et al. Chemical synthesis and magnetic study of nanocrystalline thin films of cobalt spinel ferrites. Solid State Communications. 1998; 107:471-476. http://dx.doi. org/10.1016/S0038-1098(98)00265-8

13. Rao BP and Rao KH. Effect of sintering conditions on resistivity and dielectric properties of Ni-Zn ferrites. Journal of Materials Science. 1997; 32:6049-6054. http://dx.doi. org/10.1023/A:1018683615616

14. Sepelak V, Baabe D, Mienert D, Schultze D, Krumeich F, Litterst FJ et al. Evolution of structure and magnetic properties with annealing temperature in nanoscale highenergy-milled nickel ferrite. Journal of Magnetism and Magnetic Materials. 2003; 257:377-386. http://dx.doi. org/10.1016/S0304-8853(02)01279-9

15. Koops CG. On the Dispersion of Resistivity and Dielectric Constant of Some Semiconductors at Audiofrequencies. Physical Review. 1951; 83:121-124. http://dx.doi.org/10.1103/ PhysRev.83.121

16. Costa ACFM, Tortella E, Morelli MR and Kiminami RHGA. Synthesis, microstructure and magnetic properties of Ni-Zn ferrites. Journal of Magnetism and Magnetic 
Materials. 2003; 256:174-182. http://dx.doi.org/10.1016/ S0304-8853(02)00449-3

17. Kodama RH, Berkowitz AE, McNiff EJ and Foner S. Surface Spin Disorder in $\mathrm{NiFe}_{2} \mathrm{O}_{4}$ Nanoparticles. Physical Review Letters. 1996; 77(2):394-97. PMid:10062440. http://dx.doi. org/10.1103/PhysRevLett.77.394

18. Sepelak V, Bergmann I, Feldhoff A, Heitjans P, Krumeich F, Menzel D et al. Nanocrystalline nickel ferrite, $\mathrm{NiFe}_{2} \mathrm{O}_{4}$ : Mechanosynthesis, nonequilibrium cation distribution, canted spin arrangement, and magnetic behavior. Journal of Physical Chemistry C. 2007; 111(13):5026-5033. http://dx.doi. org/10.1021/jp067620s

19. Rajendran M, Pullar RC, Bhattacharya AK, Das D, Chintalapudi $\mathrm{SN}$ and Majumdar CK. Magnetic properties of nanocrystalline $\mathrm{CoFe}_{2} \mathrm{O}_{4}$ powders prepared at room temperature: Variation with crystallite size. Journal of Magnetism and Magnetic Materials. 2001; 232(1-2):71-83. http://dx.doi.org/10.1016/ S0304-8853(01)00151-2

20. Srivastava M, Chaubey $\mathrm{S}$ and Ojha $\mathrm{AK}$. Investigation on size dependent structural and magnetic behavior of nickel ferrite nanoparticles prepared by sol-gel and hydrothermal methods. Materials Chemistry and Physics. 2009; 118(1):174-180. http:// dx.doi.org/10.1016/j.matchemphys.2009.07.023
21. Weast RC. Handbook of Chemistry and Physics. 68th ed. CRC Press, Inc.; 1987.

22. Senthilkumar B, Selvan RK, Vinothbabu P, Perelshtein I and Gedanken A. Structural, magnetic, electrical and electrochemical properties of $\mathrm{NiFe}_{(2)} \mathrm{O}_{(4)}$ synthesized by the molten salt technique. Materials Chemistry and Physics. 2011; 130(1-2):285-292. http://dx.doi.org/10.1016/j. matchemphys.2011.06.043

23. German RM. Sintering Theory And Practice. New York: John Willy \& Sons, Inc.; 1996.

24. Li ZY, Liu BG, Zhou KC, Zhang D and Zhang L. Microstructure and Dc Electrical Conductivity of Spinel Nickel Ferrite Sintered in Air and Nitrogen Atmospheres. Materials Research Bulletin. 2010; 45(11):1668-71. http://dx.doi.org/10.1016/j. materresbull.2010.07.003

25. Mahalakshmi S and Manja KS. Ac electrical conductivity and dielectric behavior of nanophase nickel ferrites. Journal of Alloys and Compounds. 2008; 457:522-525. http://dx.doi. org/10.1016/j.jallcom.2007.03.045

26. Skomski R. Nanomagnetics. Journal of Physics-Condensed Matter. 2003; 15(20):84. http://dx.doi.org/10.1088/0953$8984 / 15 / 20 / 202$ 